\title{
Comparative studies on cooking qualities of aged brown and polished rice, Oryza sativa
}

\author{
V. K. Tiwari ${ }^{1}$, Neha Pachlasiya ${ }^{2}$ and H. L. Sharma ${ }^{3}$ \\ Department of Post-Harvest Process and Food Engineering, Faculty of Agricultural Engineering, Jawaharlal \\ Nehru Krishi Vishwa Vidyalaya, Jabalpur 482004 (MP) India
}

\begin{abstract}
A comparative study of cooking quality of brown rice and polished rice (i.e. volume, length, breadth, thickness expansion ratio, water uptake ratio and optimum cooking time) with respect to different time was carried out in the laboratory of Post-Harvest Process and Food Engineering College of Agricultural Engineering, JNKVV, Jabalpur. Brown rice and polished rice was procured from Singhai Rice Mill village Panagar, Jabalpur and kept for three months at ambient condition. Sample from aged raw and polished rice were withdrawn and cooked for 3, 5 and 7 minutes for evaluation of cooking quality. It was observed that the length expansion ratio (LER) of polished rice was maximum (1.46) as compared to brown rice for all type of cooking, breadth expansion ratio was maximum (1.45), thickness expansion ratio (TER-1.22), volume expansion ratio of polished rice (VER-2.6), the water uptake of polished rice was maximum (1.78) as compared to brown rice. However cooking time was minimum for polished rice when cooked for 3, 5 and 7 minutes as compared to brown rice.
\end{abstract}

KEY WORDS: BROWN RICE, POLISHED RICE LENGTH, BREADTH, VOLUME EXPANSION RATIO, WATER UPTAKE RATIO, OPTIMUM COOKING TIME

\section{INTRODUCTION}

Rice (Oryza sativa $L$ ) is a cereal grain and an important staple food for a large part of the world's human population. Among cereals, rice is even more nutritious than wheat. India is the world's largest producer of rice. India produced 105 million tonnes rice in the year 2017 (www. fci.gov.in). Brown rice is unpolished whole rice grain

\section{ARTICLE INFORMATION:}

*Corresponding Author: iitkgp84@yahoo.co.in

Received $21^{\text {st }}$ July, 2017

Accepted after revision 25 $5^{\text {th }}$ Sep, 2017

BBRC Print ISSN: 0974-6455

Online ISSN: 2321-4007 CODEN: USA BBRCBA

Thomson Reuters ISI ESC and Crossref Indexed Journal

NAAS Journal Score 2017: 4.31 Cosmos IF: 4.006

๑ A Society of Science and Nature Publication, 2017. All rights reserved.

Online Contents Available at: http//www.bbrc.in/

DOI: $10.21786 / \mathrm{bbrc} / 10.3 / 30$ that is produced by removing only the husk using the rubber rolls. Distinguish factor is its unpolished features and not the colour. Post-harvest researchers reported that the milling recovery in brown rice is 10\% higher than polished rice. It contain minerals (prevents beriberi) and high fat (energy source). Also it has been reported that brown rice contains high phytic acid (antioxidant, anti-cancer); it decreases serum cholesterol (prevents 
cardio-vascular diseases) and is considered a low glycemic index food (low starch, high complex carbohydrates which decrease risk to type 2 diabetes). Moreover, brown rice contains large amount of insoluble fibre, which may prevent a variety of cancers. There are many benefits of brown rice. The fuel savings in milling process is 50-60\% because the polishing and whitening steps are eliminated. In this way the milling time is also shortened with less labour requirements, also, the enhancement in output volume and the economy in milling indicated the business opportunity in brown rice (Rogelio, 2003 Kumar et al., 2017).

Brown rice when being cooked, becomes a sticky or pasty mass, swells only slightly and leaves a thick gruel. All these cooking properties may not be accustomed to most consumers who prefer fluffy and hard texture. The desired cooking properties can normally be obtained by storing freshly-harvested rice for at least 3-6 months (Swamy et al. 1978). Ageing involves changes in physical and chemical properties of the rice grain. Starch, protein and lipids are the main grain components which affect cooking and eating quality (Villareal et al.1976). An unusual property of rice is that its cooking quality depends on its age after harvest. New rice swells poorly during cooking. This undesirable property gradually changes during storage for few months (Patindol, et al. 2005 and Sowbhagya 2001).

\section{MATERIALS \&t METHODS}

Brown rice and polished rice were procured from modern rice mill. The rice was stored at ambient condition for four month in the laboratory Post Harvest Process and Food Engineering Department, College of Agricultural Engineering, JNKVV, Jabalpur. Then the samples were withdrawn from the stored rice stock and cooked in the laboratory for different time to evaluate the cooking quality including optimum cooking time.

\section{MOISTURE CONTENT DETERMINATION}

Moisture content of sample was determined by standard air oven method (AOAC method). The samples were dried in hot air oven maintained at $103 \pm 1^{\circ} \mathrm{C}$ for 24 hours.

$$
\text { Moisture\% }(w . b .)=\frac{\text { Loss in weight of sample }}{\text { Initial weight of sample }}
$$

\section{COOKING QUALITY}

Rice expands length wise, breadth wise and thickness wise during cooking by absorbing water. To determine rice length after cooking and rice breadth after cooking 20 milled grains are pre-soaked to 10-30 minute and placed directly into boiling water by directly dropping until its optimum cooking time .The length, breadth and thickness are measured and the average worked out. The experiment was aimed to determine cooking properties. Rice is considered to have good cooking quality if it has high length expansion ratio (VER), volume expansion ratio (LER), water uptake ratio (WUR) and minimum Cooking time (CT) (Juliano, 1985). Length and volume expansion ratio (VER) and water absorption are desirable for the food service industry as they lead to a fuller plate for the same amount of rice. Length expansion ratio i.e. the ratio of the length of cooked rice to that of raw rice was calculated

$$
\text { Length expansion ratio }(L E R)=\frac{\text { Lengt } h \text { of cooked rice }}{\text { Lengt } h \text { of raw rice }}
$$

Breadth expansion ratio i.e. the ratio of the breadth of cooked rice to that of raw rice was calculated

$$
\text { Breadth expansionratio }(B E R)=\frac{\text { Breadt } h \text { of cooked rice }}{\text { Breadt } h \text { of raw rice }}
$$

Thickness expansion ratio i.e. the ratio of the thickness of cooked rice to that of raw rice was calculated

$$
\text { Thickness expansion ratio }(T E R)=\frac{\text { Thickness of cooked rice }}{\text { Thickness of raw rice }}
$$

\section{VOLUME EXPANSION RATIO}

Volume expansion ratio (VER) was calculated i.e. the ratio of the volume of the cooked rice to the initial volume of the raw rice, using toluene displacement method.

$$
\text { Volume expansion ratio }(V E R)=\frac{\text { Volume of the cooked rice }}{\text { volume of raw rice }}
$$

\section{WATER UPTAKE RATIO}

Water uptake ratio (WUR) as ratio of water absorbed during cooking to cooked rice weight was calculated by weight of cooked rice and weight raw rice.

$$
\text { Water uptake ratio }(\text { WUR })=\frac{\text { Weight of cooked rice }}{\text { Weight of raw rice }}
$$

\section{OPTIMUM COOKING TIME (OCT)}

It is the time taken by a predetermined weight of rice to cook completely. Brown rice and polished rice $(2 \mathrm{~g})$ samples were taken in test tube and cooked in $100 \mathrm{ml}$ distilled water in a hot water bath at $100^{\circ} \mathrm{C}$. The cooking time was determined by taking out 20 grains at different time intervals during cooking and pressing them between two glass plates until atleast $90 \%$ of rice had no longer centres, which is considered as optimum cooking time. 


\section{RESULTS AND DISCUSSION}

A comparative study of cooking quality of brown rice and polished rice was initiated to find out significance of polishing of rice. Three aged brown and polished rice was cooked for three minute and 1.135 times increases in length were observed with linear expansion. The graph reveals about the forecast value of length expansion of polished rice at the time of cooking. The linear relation line will always provide the best result for the relation between time of cooking and expansion of polished rice. The maximum value of $\mathrm{R}$ observed as $97 \%$ and this variability was explained in the expansion of polished rice through the cooking time.It shows that the expansion of polished rice is certainly dependent on the cooking time means the cooking time is one of the best factor. The length expansion ratio for polished and brown rice is represented by models

$$
\begin{array}{r}
Y=0.0677 x+0.98 \\
Y=0.0286 x+0.99
\end{array}
$$

The results of breadth expansion of polished rice (for 5 minute cooking) showed 1.42 times increase as shown in fig. 2. It is observed that the polished rice expand at faster rate. The maximum value of $\mathrm{R}$ observed as 99\% and this variability was explained in the expansion of polished rice through the cooking time and the breadth expansion ratio for polished rice and brown rice are represented by models

$$
\begin{aligned}
& Y=0.0781 x+1.0013 \\
& Y=0.054 x+0.9862
\end{aligned}
$$

The graph shows thickness expansion of polished rice increases at faster rate for 7 minute cooking time with 1.22 times increase in thickness. The linear behaviour is shown in fig. 3. The maximum value of Robserved as 99\% and this variability was explained in the thickness expansion of polished rice through cooking time. The thickness expansion ratio for polished rice and brown rice are represented by models.

$$
\begin{aligned}
& Y=0.0318 x+0.9985 \\
& Y=0.0221 x+0.9638
\end{aligned}
$$

The volume expansion of polished rice was higher (for 3 minute cooking time) with1.8 times increase in volume as shown in fig. 4. It is observed that the polished rice expand at faster rate. The maximum value Robserved as 99\% and this variability was explained in the expansion of polished rice through the cooking time. The expansion behaviour can be expressed by following models:

$$
\begin{array}{r}
Y=0.257 x+1.0112 \\
Y=0.1234 x+0.9989
\end{array}
$$

The water uptake ratio increased linearly for polished rice (for 5 minute cooking time) with 1.58 times increase as shown in fig. 5 . The maximum value of $\mathrm{R}$ observed as 99\% and this variability was explained in the expansion of polished rice and the water uptake ratio of polished and brown rice behaviour can be shown by following models

$$
\begin{aligned}
& Y=0.1066 x+1.0225 \\
& Y=0.0916 x+0.9865
\end{aligned}
$$

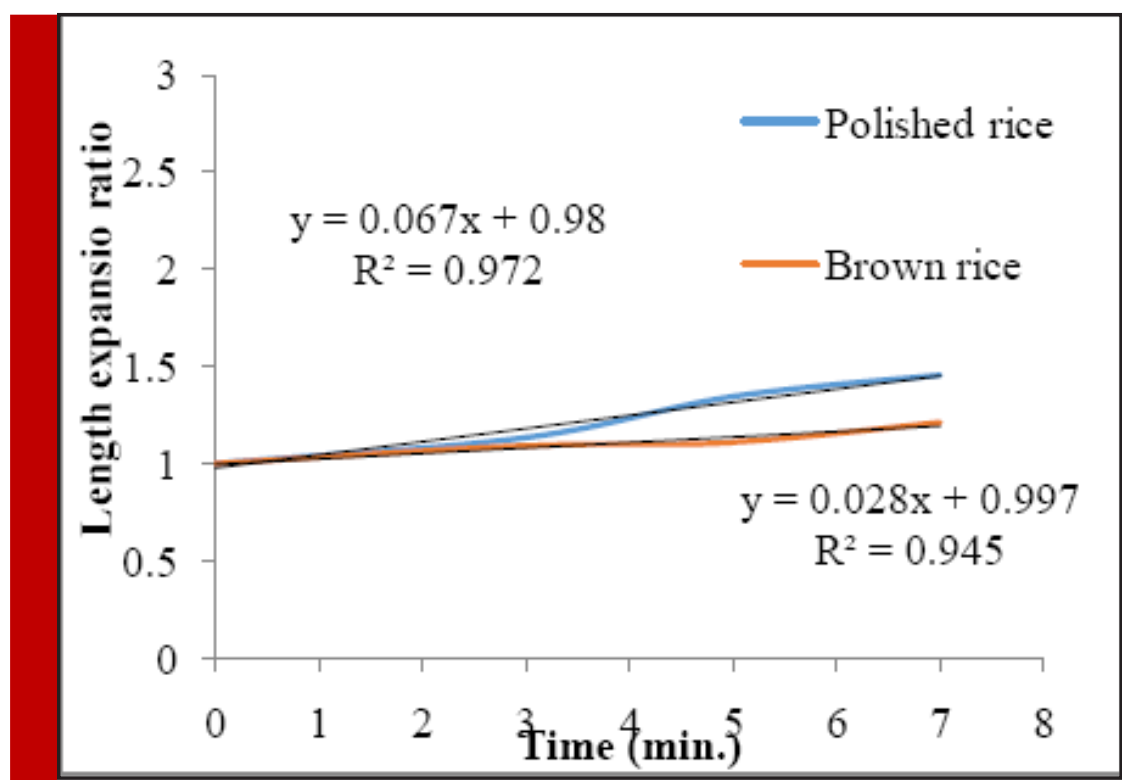

FIGURE 1. Length expansion ratio of Polished and Brown rice 


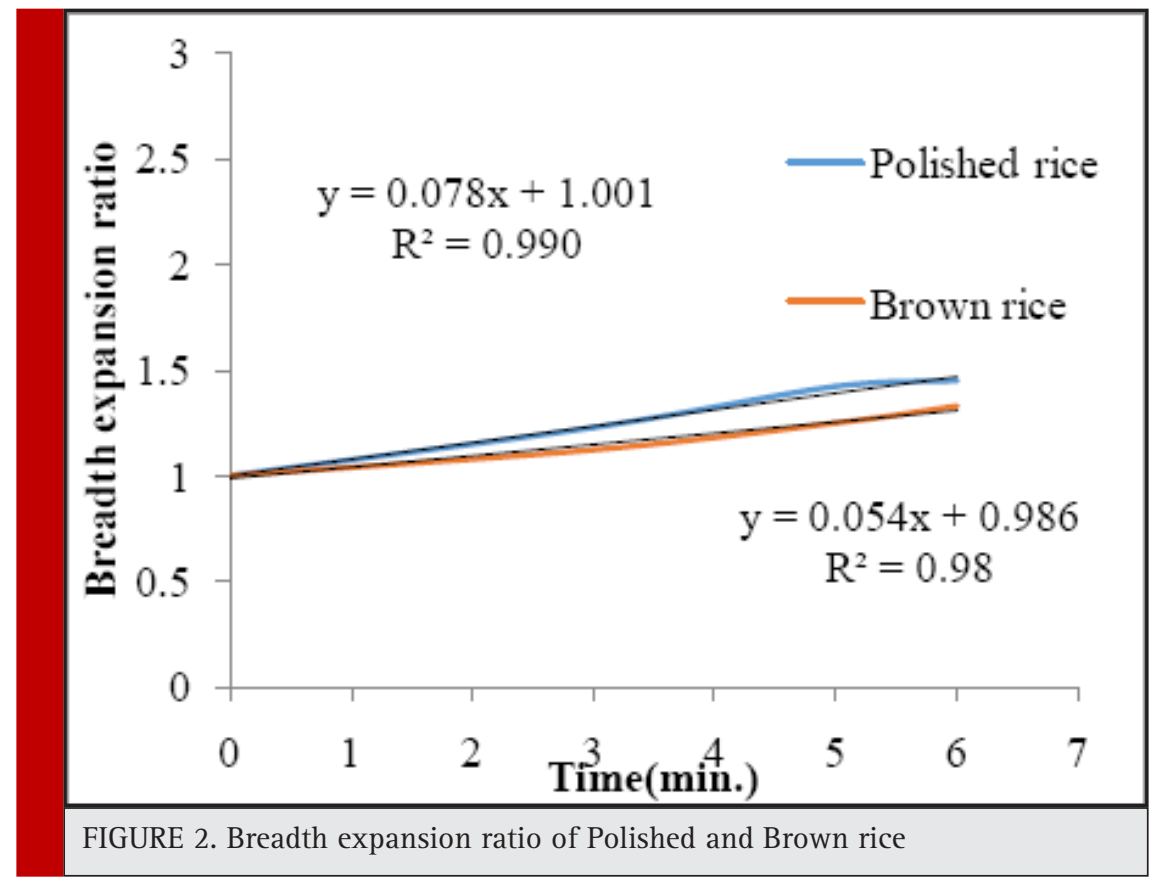

Less expansion is observed in brown rice in all three dimensions (length. breadth and thickness) because the kernel is covered with thin layer of bran which contains oil so that expansion ratio was less in brown rice, Although the brown rice takes more time in cooking but water uptake ratio is high in polished rice. In this study length expansion ratio, width expansion ratio, thickness expansion ratio, volume expansion ratio and water uptake ratio of brown and polished rice were determined.
Rice is considered to have good cooking quality if it has high expansion ratio. Water to rice ratio affected chewiness of cooked rice. Ratio of water to rice also affected the eating quality rice (Daomukda 2011).

Length expansion ratio of brown and polished rice is shown in figure 1. Cooking time of rice varied from 3-7 minutes (with 2 min interval). Polished rice had highest LER as compared to brown rice. This shows the positive correlation of LER with time of cooking (Gujral 2003).

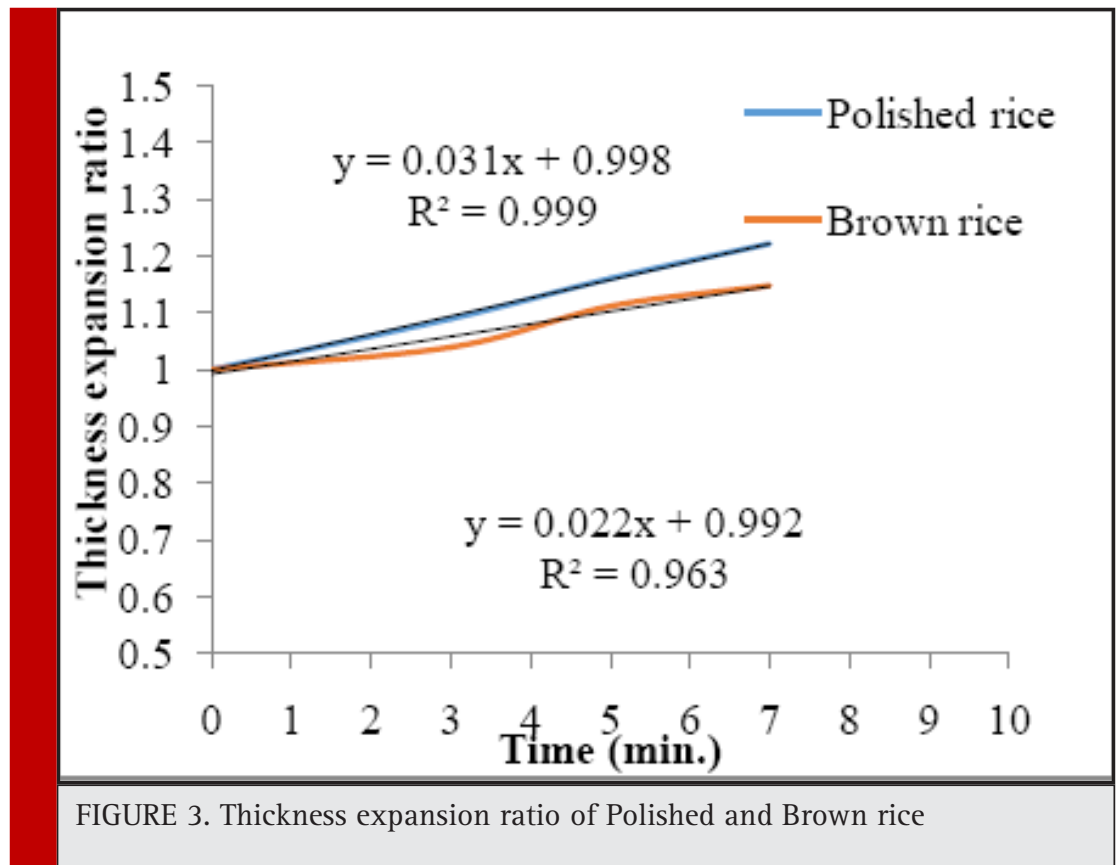



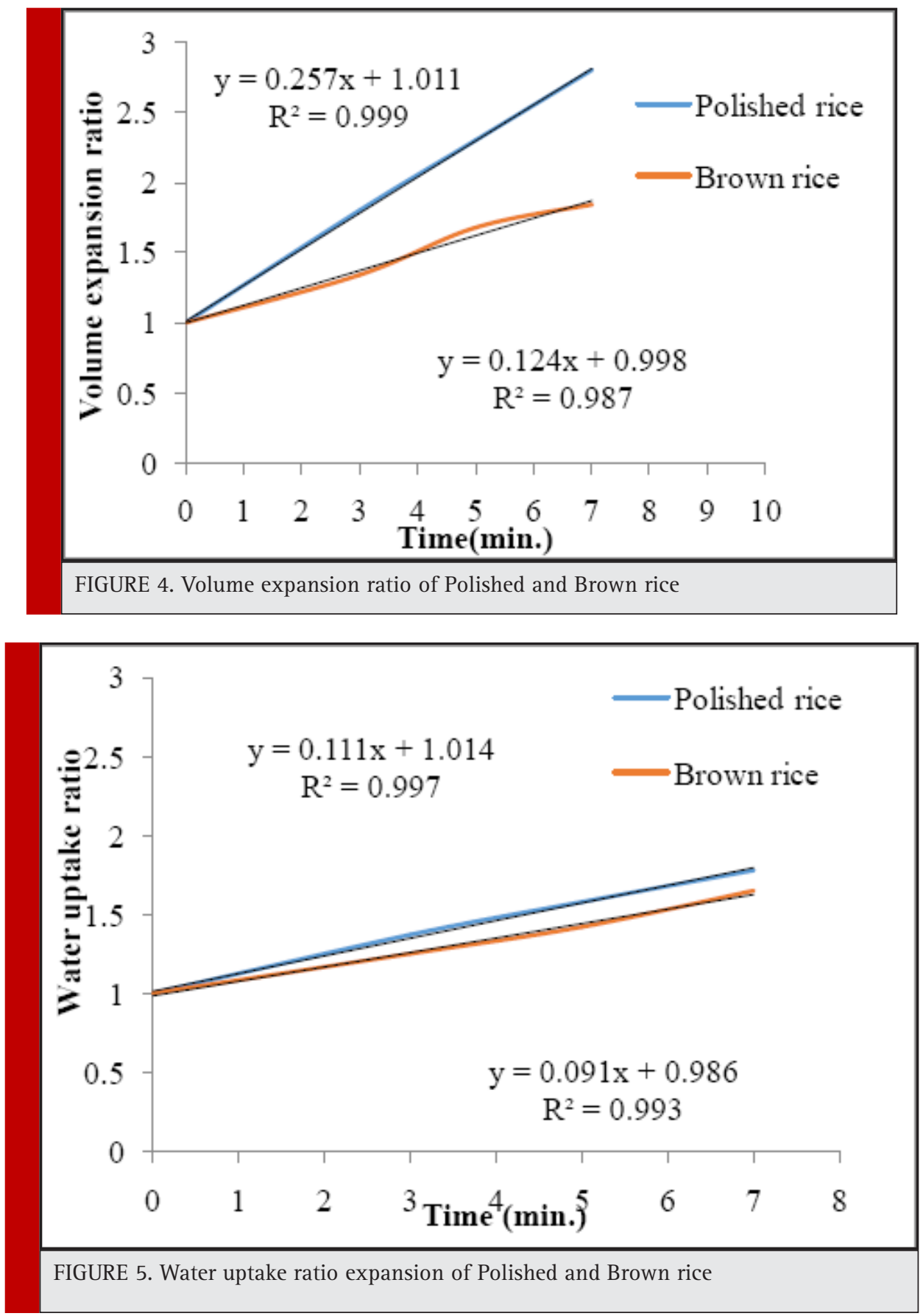

Similar results of BER, VER and WUR were also obtained in brown and polished rice. A greater elongation ratio of polished rice is due to absence of bran layer which allows water to enter inside the kernel as compared to brown rice. The results are in agreement with Kumar et al. (2017).

\section{REFERENCES}

AOAC (1980) Association of Official Analytical Chemists, Official methods of analysis, $13^{\text {th }}$ Edition, Washington, DC, USA.
Juliano B.O. (1985) Rice: Chemistry and Technology. $2^{\text {nd }}$ ed., American Association of cereal Chemists, St. Paul, M.N

Rogelio VC (2003) The National Campaign to Combat Hidden Hunger through Brown In: Consultative Meeting on Nutritional Aspect of Brown Rice, September 2003, Food and Nutrition Research Inst., Manila, Philippines.

Swamy YM, Sowbhagya CM and Bhattacharya KR (1978) Changes in the physiocochemical properties of rice with aging. Journal of the science of Food and Agriculture 29: 625627. 
Villareal CP, Maranville JW and Juliano BO (1991).Nutrient content and retention during milling of brown rice from the international Rice Research Institute. Cereal Chem.68:437-440.

Patindol, J., Wang, Y.J. and Jane, J. I. 2005 Structure-functionality changes in starch following rough rice storage. Starch/ Starke, 2005,57,197e207.

Sowbhagya, C.M. and Bhattacharya, K.R. 2001 Changes in pasting behaviour of rice during ageing. Journal of Cereal Science.2001,34:115e124.

Daomukda, M., Moongngarm,A., Payakapol, L. and Noisuwan, A. 2011 Effect of cooking methods on physicochemical properties of brown rice. $2^{\text {nd }}$ international conference on Environment Science and Technology, IACSIT Press, Singapore, 2011,6(2),1-4.

Gujral, H.S. and Kumar,V. Effect of accelerated ageing on the physicochemical and textural properties of brown and milled rice. Journal of Food Engineering, 2003,59,117-121.

Kumar, A.,Bhople,S.,Kumar,N.,and Tiwari,V.K.2017 Effect of ageing, moisture contents and storage structures on nutritional and cooking characteristics of brown rice during storage, J. Food Corporation of India 6 (22),793-800.www.fci. gov.in 